\title{
Changes in Ultrastructure and Sensory Characteristics on Electro- magnetic and Air Blast Freezing of Beef during Frozen Storage
}

\author{
Yun-Sang Choi, Su-Kyung Ku, Ji-Yun Jeong, Ki-Hong Jeon, and Young-Boong Kim* \\ Research Group of Convergence Technology, Korean Food Research Institute, Seongnam 463-746, Korea
}

\begin{abstract}
The ultrastructure in the beef muscle of the electro-magnetic resonance and air blast freezing during the frozen storage, and the changes in the quality characteristics after thawing were evaluated. The size of ice crystal was small and evenly formed in the initial freezing period, and it showed that the size was increased as the storage period was elapsed $(p<0.05)$. The beef stored by the electro-magnetic resonance freezing showed the size of ice crystal with a lower rate of increase than the air blast freezing during the frozen storage. The thawing loss of beef stored by the electro-magnetic resonance freezing was significantly lower than the air blast freezing during frozen storage $(p<0.05)$, and it showed that the thawing loss of the round was higher than the loin. Water holding capacity decreased as the storage period became longer while the electromagnetic resonance freezing was higher than the air blast on 8 month $(p<0.05)$. As a result of sensory evaluation, the beef stored by the electro-magnetic resonance freezing did not show the difference until 4 months, and it showed higher acceptability in comparison with the beef stored by the air blast freezing. Thus, it is considered that the freezing method has an effect on the change in the ultrastructure and quality characteristics of the beef.
\end{abstract}

Key words: electro-magnetic, freezing, ultrastructure, thawing loss, sensory characteristics

\section{Introduction}

Freezing is a much preferred technique to preserve food for a long period of time (Alizadeh et al., 2007; Kidmose and Martens, 1999). The concentration of the aqueous phase present in the cell will increase when extra ice crystals will appear. This phenomenon induces water diffusion from surrounding locations. The intracellular ice also induces an increase in the concentration of the intracellular aqueous phase. The size and location of ice crystals are considered the most important factors affecting the textural quality of frozen food (Martino et al., 1998). The traditional freezing process is generally slow, resulting in large extracellular ice-crystal formations (Bello et al., 1982; Fennema et al., 1973), which cause texture damage, accelerate enzyme activity, and increase oxidation rates during storage and after thawing. On the other hand, rapid freezing (e.g., cryogenic freezing) can reduce the ice-crystal size and produce a large number of smaller ice

\footnotetext{
*Corresponding author: Young-Boong Kim, Processing Technology Research Group, Convergence Technology Research Division, Korea Food Research Institute, Sungnam 463-746, Korea. Tel: +82-31-780-9180, Fax: +82-31-780-9076, E-mail: kybaaa@kfri.re.kr
}

crystals that cause less damage due to its high degree of super-cooling (Kalichevsky et al., 1995; Kim and Hung, 1994; Otero et al., 2000). The cause of the undesirable physical-chemical modifications during freezing is the crystallization of water and sometimes solutes. Minimizing the time of the phase change period contributes to optimum product quality (Brennan et al., 1990).

The quick freezing is the method that damages the cellular tissue, and it can be minimized, as compared with the slow freezing, because the small and many ice crystals formation and being outside of the beef cell (Reid, 1997). The air blast-type, flat contact-type, and cryogenic freezing method have been utilized as the general quick freezing (Lakshmisha et al., 2008; Norton et al., 2009). It has been reported that when freezing meat, the lower temperature the more the size of ice crystal within the tissue become smaller, and the size of ice crystal has an effect on the thawing loss and cooking loss (Miller et al., 1962; Oh et al., 1984; Park, 1991). The electro-magnetic resonance freezing disturbs the crystallization of water molecules by adding energy to and vibrating the frozen subjects in the magnetic field environment. Iwasaka et al. (2011) have reported that this is the freezing method that can reduced the destruction of cellular tissue by simultaneously freezing and being outside of the frozen subjects, 
by inhibiting the migration of water molecule.

Therefore, the objective of this study was to investigate the effects of ultrastructure and sensory characteristics on the frozen beef stored by the electro-magnetic resonance and the air blast freezing in order to minimize the quality degradation during long-term storage.

\section{Materials and Methods}

\section{Samples}

The samples used in this study were the loin (M. longissimus dorsi) and the round (M. semimembranosus, $M$. biceps femoris, M. semitendinosus) of beef deboned and cut in packing plant after one day since the slaughter. The samples for the ultrastructure analysis were formed as molds of $3 \times 2 \times 1 \mathrm{~cm}$ (length $\times$ width $\times$ height) in the direction of muscle texture, and put them in petri dish and were frozen by sealing with parafilm. The sample for physiochemical analysis was $2-4 \mathrm{~cm}$ (500 g) unit, and this sample was then placed in polyethylene bags, vacuum packaged using a vacuum packaging system.

\section{Freezing and thawing}

The samples were conducted by the electro-magnetic resonance and air blast freezing. The electro-magnetic resonance freezing (AVI Co., Japan) was frozen to $-55^{\circ} \mathrm{C}$ by using the freezer (DineJeju Co., Korea). The sample by the air blast freezing was frozen to $-45^{\circ} \mathrm{C}$ in the Korea Food Research Institute. All frozen beef samples were stored in a freezer at $-20^{\circ} \mathrm{C}$. A data logger $(176 \mathrm{~T} 4$, Testo, Germany) temperature recording devices and a thermocouple (NiCr-Ni thermocouple, SEF GmbH, Germany) as a sensor was used. The thawing of sample was performed until the core temperature of samples become $0^{\circ} \mathrm{C}$ using a microwave oven (RE-551B, 2450MHz, 700W, Samsung Co., Korea). The central part were reached up to $0^{\circ} \mathrm{C}$, the beef was thawed for $12 \mathrm{~min} 30 \mathrm{~s}$, and then overturned thawed for $12 \mathrm{~min} 30 \mathrm{~s}$.

\section{Analysis items and methods}

The frozen beef by the electro-magnetic resonance and the air blast freezing was experimented by thawing after frozen storage at 2-mon intervals during 8 mon. Each experiment was analyzed by repeating of three times.

\section{Ice crystal size}

In order to measure the ultrastructure and the ice crystal, the samples were made of the tissue section by cutting the muscle to a cross-section of $2 \mathrm{~mm}$ thick with a surgi- cal blade (feather) in the frozen state at $-20^{\circ} \mathrm{C}$. The tissue sections were put on SEM (scanning electron microscope) holder and were fixed. The tissue sections were measured by using SEM (Hitachi S-3500N Cooling Stage, Hitachi Co Ltd., Japan) which is a differential scanning microscope. The samples were observed by a RBE (Robinson Backscattered Electron) detector under the measurement conditions of an acceleration voltage of $20 \mathrm{kV}$, the pressure of $50 \mathrm{~Pa}$, and the magnification of 100 times. The ice crystal size was obtained as the average scale bar using with the callipus built-in the machine from SEM.

\section{Thawing loss}

The thawing loss was calculated as a percentage by measuring the drip amount until the temperature of deep part was reached to $0^{\circ} \mathrm{C}$.

Thawing loss $(\%)=\{($ weight before thaw - weight after thaw) / weight before thaw $\} \times 100$

\section{Water holding capacity (WHC)}

WHC using the modified Kristensen and Purslow (2001) method, after chopping the sample with a crusher, the crushed sample of $5 \mathrm{~g}$ was put into a centrifuge tube and then was heated for $30 \mathrm{~min}$ in water bath of $70^{\circ} \mathrm{C}$. After cooling the heated samples at the room temperature, the sample was centrifuged at $1,000 \mathrm{rpm}$, and $20^{\circ} \mathrm{C}$ for 10 min and then the amount of separated gravy and the total water content were measured, and the measured values were calculated by substituting in the following formula.

WHC $(\%)=($ total water content - separated water content) $\times 0.951 * /$ total water contents $\times 100$

*0.951: pure water amount for meat moisture which is separated under $70^{\circ} \mathrm{C}$

\section{Sensory characteristic}

A sensory characteristic of samples was carried out based on appearance, flavor, texture, taste and overall acceptability with a scale of 9-points, and by 15 panels who are chosen among personnel with more than 1 year of experience in meat-related and sensory testing. Selection of panelists was performed according to sensory evaluation procedure (Lawless and Heymann, 1999). Its score is indicated by 1-point (very poor) to 9-point (very good). For this sensory test, the samples are cut to $1 \mathrm{~cm}$ of thickness and heated using an electrical grill (HD- 
4417, Phillips, Netherlands) until the core temperature of meat reaches $75^{\circ} \mathrm{C}$, after which was provided to the panels for sensory evaluation on a white dish. This analysis was conducted using the hedonic test described by Bergara-Almeida and da Silva (2002).

\section{Statistical analysis}

All tests were done at least three times for each experimental condition and mean values are reported. An analysis of variance was performed on all the variables using the general linear model (GLM) procedure of the SAS (Statistical Analysis Systems Institute, 2002) statistical package. Duncan's multiple range test $(p<0.05)$ was used to determine the differences between treatment means. The statistical analysis for each parameter combines the data from three batches.

\section{Results and Discussion}

\section{Scanning electron microscope (SEM)}

The ultrastructure change, according to the frozen storage of the electro-magnetic resonance and the air blast freezing, is shown in Fig. 1. Bomben et al. (1983) have reported that, as a result of observing the ice morphology using SEM, the bright part of tissue showed the images that are called the solute of cell sap, cell membrane, and cell wall. The dark part was the ice. In addition, it has been reported that the difference of the intensity of the light is the difference of the size of the ice crystal by partial sublimation during the freeze-etching, and it results with the water-soluble solute and the insoluble structures of the tissue showing that the difference is not sublimated. In this study, the ice crystal was significantly

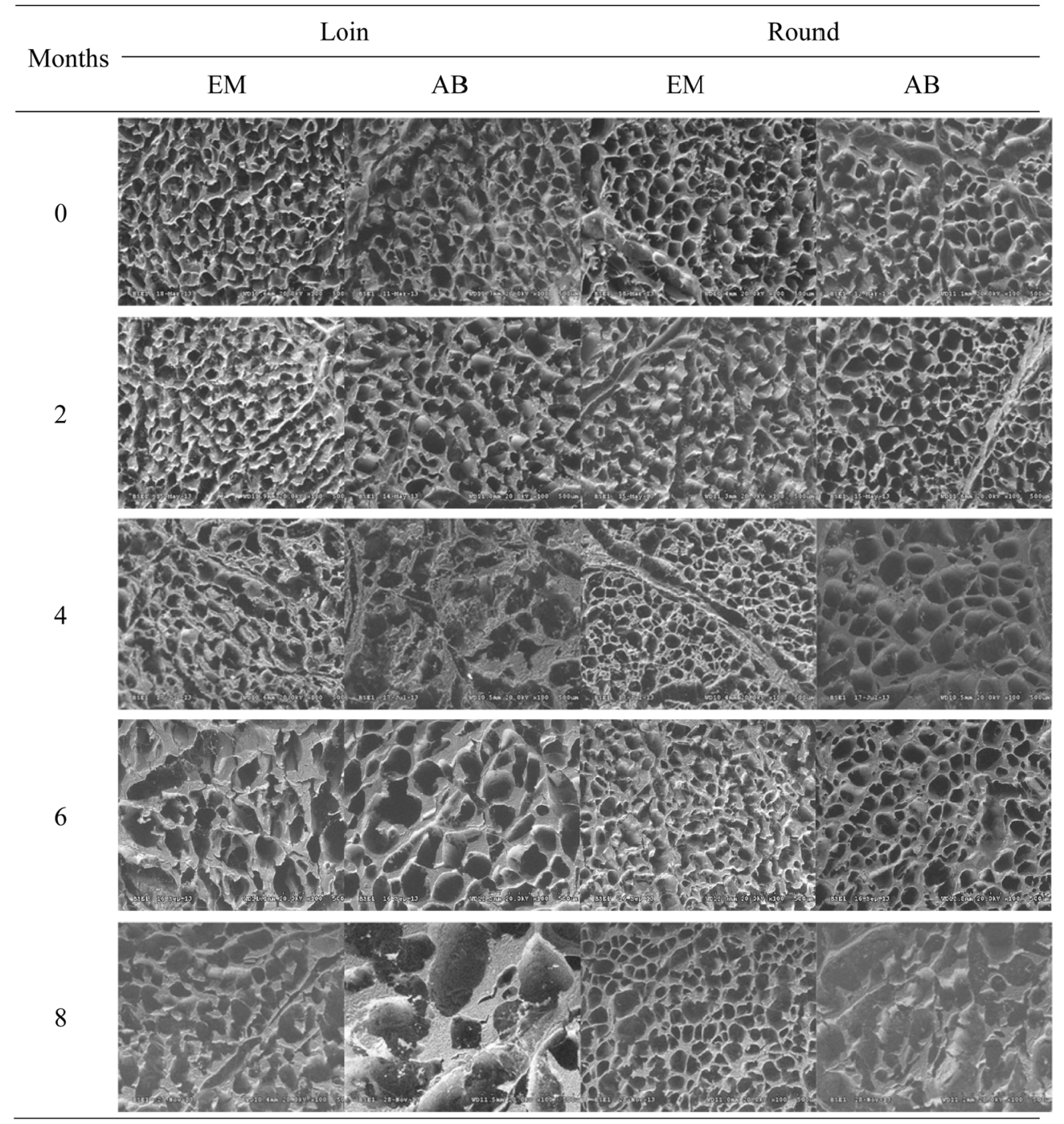

Fig. 1. Changes in morphological characteristics on electro-magnetic resonance and air blast freezing of loin and round during frozen storage for 8 mon (scale bar $=\mathbf{5 0 0} \mu \mathrm{m})$. EM: Electro-magnetic resonance freezing, AB: Air blast freezing. 
formed, and the destruction of cell wall was shown in the ultrastructure of the loin and the round by the air blast freezing. However, the electro-magnetic resonance freezing showed the narrow gap between the initial muscle fiber, and the small, and uniform ice crystals. Bomben et al. (1983) have reported that the morphologic change of the cell wall and cell membrane does not almost occur under the quick freezing. Jeong et al. (1999) have reported that, during the slow freezing the shape is crushed, or the irregular crack occurred due to the dehydration of tissue by the water-soluble substances of the muscle fiber tissue which is slowly frozen. The ice crystal is generated in the tissue, and the destruction of cellular tissue occurred less often from the quick freezing. Also, the results showed that the destruction of cellular tissue gradually occurred as the storage become longer. The beef stored by the electro-magnetic resonance freezing showed that the destruction of cellular tissue occurring during the storage happened less often as compared with the beef stored by the air blast freezing.

\section{Ice crystal size}

The ice crystal size changed according to the frozen storage of the electro-magnetic resonance and the air blast freezing, as shown in Table 1. The ice crystal size of the beef loin in the early stage of freezing ( 0 mon) was smaller than $46.61 \mu \mathrm{m}$, which is the ice crystal size of the beef loin stored by the air blast freezing, at $42.08 \mu \mathrm{m}$ in the electro-magnetic resonance freezing. The size of ice crystals by the electro-magnetic resonance freezing during frozen storage for 8 mon was the smaller than that of the air blast freezing $(46.61-107.20 \mu \mathrm{m})$ at the range of 42.08-90.20 $\mu \mathrm{m}$. For the part of the loin, the ice crystal size significantly increased from the range of 42.08-46.61 $\mu \mathrm{m}$ in the initial freezing period to the range of 90.20 $107.20 \mu \mathrm{m}$ on the $8 \mathrm{mon}$ after freezing storage, regardless of the freezing $(p<0.05)$. The rate of size increase of ice crystal of the sample by the electro-magnetic resonance freezing during frozen storage was lower than the $232.5 \%$, which is the rate of increase of the air blast freezing sample, at $214.3 \%$ after 8 mon in comparison with the initial period. The initial size of ice crystal of the round by the electro-magnetic resonance freezing was $46.79 \mu \mathrm{m}$, and the air blast freezing treatment plot was $51.08 \mu \mathrm{m}$ so that the round by the electro-magnetic resonance freezing showed a significant difference and was smaller than the air blast freezing $(p<0.05)$. As the storage time became longer, the round went from the range of 46.79-51.08 $\mu \mathrm{m}$ in the initial freezing period to the range of 92.60-108.13 $\mu \mathrm{m}$ at 8 mon. Consequently, the round showed that the ice crystal size significantly increased similarly to the loin, regardless of the freezing method. Bomben et al. (1983) and Chassagne-Berces et al.(2009) have reported that, because the space in the cellular tissue is kept in the narrowing state under quick freezing, the destruction of cell membrane occurred less often. For this reason, we suggest that, as the storage period is elapsed, the ice crystal size is increased, regardless of the freezing method. Because the ice crystal size of the beef stored by the electro-magnetic resonance freezing is small and uniformly formed, the meat quality is less affected during the thawing of beef.

\section{Thawing loss}

The change in the thawing loss, according to the frozen storage of the electro-magnetic field and the air blast freezing, is shown in Table 2. The thawing loss during storage for 8 mon was the range of $0.66-2.43 \%$ for the electro-magnetic resonance freezing, and the loss by the air blast freezing was the range of $0.92-3.10 \%$. There was no significant difference between the freezing methods, except for 4 mon. The thawing loss of the beef stored by the electro-magnetic resonance freezing showed relatively smaller than the air blast freezing. We judged that

Table 1. Changes in ice crystal size on electro-magnetic resonance and air blast freezing of loin and round during frozen storage for 8 mon (Unit: $\mu \mathrm{m})$

\begin{tabular}{|c|c|c|c|c|}
\hline \multirow{2}{*}{ Months } & \multicolumn{2}{|c|}{ Loin } & \multicolumn{2}{|c|}{ Round } \\
\hline & EM & $\mathrm{AB}$ & EM & $\mathrm{AB}$ \\
\hline 0 & $42.08 \pm 0.30^{\mathrm{bE}}$ & $46.61 \pm 0.29^{\mathrm{aE}}$ & $46.79 \pm 0.36^{\mathrm{bE}}$ & $51.08 \pm 0.40^{\mathrm{aE}}$ \\
\hline 2 & $43.54 \pm 0.16^{\mathrm{bD}}$ & $50.60 \pm 0.17^{\mathrm{aD}}$ & $48.98 \pm 0.17^{\mathrm{bD}}$ & $55.84 \pm 0.26^{\mathrm{aD}}$ \\
\hline 4 & $76.25 \pm 0.31^{\mathrm{bC}}$ & $88.83 \pm 1.06^{\mathrm{aC}}$ & $78.57 \pm 0.70^{\mathrm{bC}}$ & $92.13 \pm 0.34^{\mathrm{aC}}$ \\
\hline 6 & $85.01 \pm 0.30^{\mathrm{bB}}$ & $94.88 \pm 1.04^{\mathrm{aB}}$ & $81.48 \pm 0.71^{\mathrm{bB}}$ & $95.53 \pm 0.22^{\mathrm{aB}}$ \\
\hline 8 & $90.20 \pm 0.14^{\mathrm{bA}}$ & $107.20 \pm 0.68^{\mathrm{aA}}$ & $92.60 \pm 0.81^{\mathrm{bA}}$ & $108.13 \pm 0.79^{\mathrm{aA}}$ \\
\hline
\end{tabular}

EM, Electro-magnetic resonance freezing; $\mathrm{AB}$, Air blast freezing.

${ }^{\mathrm{a}, \mathrm{b}}$ Means within row with different superscripts are significantly different by freezing $(p<0.05)$.

${ }^{A-E}$ Means within column with different superscripts are significantly different by time $(p<0.05)$. 
Table 2. Changes in thawing loss on electro-magnetic resonance and air blast freezing of loin and round during frozen storage for 8 mon (Unit: \%)

\begin{tabular}{|c|c|c|c|c|}
\hline \multirow{2}{*}{ Months } & \multicolumn{2}{|c|}{ Loin } & \multicolumn{2}{|c|}{ Round } \\
\hline & EM & $\mathrm{AB}$ & EM & $\mathrm{AB}$ \\
\hline 0 & $0.66 \pm 0.11^{\mathrm{C}}$ & $0.92 \pm 0.00^{\mathrm{D}}$ & $1.25 \pm 0.12^{\mathrm{bC}}$ & $2.13 \pm 0.00^{\mathrm{aC}}$ \\
\hline 2 & $0.75 \pm 0.02^{\mathrm{C}}$ & $1.29 \pm 0.38^{\mathrm{CD}}$ & $1.54 \pm 0.10^{\mathrm{bBC}}$ & $2.54 \pm 0.22^{\mathrm{aC}}$ \\
\hline 4 & $0.81 \pm 0.08^{\mathrm{bC}}$ & $1.74 \pm 0.27^{\mathrm{aC}}$ & $1.62 \pm 0.08^{\mathrm{bBC}}$ & $2.77 \pm 0.19^{\mathrm{aBC}}$ \\
\hline 6 & $1.65 \pm 0.52^{\mathrm{B}}$ & $2.33 \pm 0.13^{\mathrm{B}}$ & $2.23 \pm 0.57^{\mathrm{bB}}$ & $3.63 \pm 0.49^{\mathrm{aAB}}$ \\
\hline 8 & $2.43 \pm 0.34^{\mathrm{A}}$ & $3.10 \pm 0.13^{\mathrm{A}}$ & $3.10 \pm 0.11^{\mathrm{bA}}$ & $4.39 \pm 0.61^{\mathrm{aA}}$ \\
\hline
\end{tabular}

EM, Electro-magnetic resonance freezing; AB, Air blast freezing.

${ }^{\mathrm{a}, \mathrm{b}}$ Means within row with different superscripts are significantly different by freezing $(p<0.05)$.

${ }^{\text {A-D }}$ Means within column with different superscripts are significantly different by time $(p<0.05)$.

Table 3. Changes in water holding capacity on electro-magnetic resonance and air blast freezing of loin and round during frozen storage for 8 mon (Unit: \%)

\begin{tabular}{|c|c|c|c|c|}
\hline \multirow{2}{*}{ Months } & \multicolumn{2}{|c|}{ Loin } & \multicolumn{2}{|c|}{ Round } \\
\hline & EM & $\mathrm{AB}$ & EM & $\mathrm{AB}$ \\
\hline 0 & $62.24 \pm 0.51^{\mathrm{aA}}$ & $59.59 \pm 0.51^{\mathrm{bA}}$ & $63.32 \pm 0.40^{\mathrm{A}}$ & $61.32 \pm 1.09^{\mathrm{A}}$ \\
\hline 2 & $60.43 \pm 0.42^{\mathrm{aB}}$ & $58.53 \pm 0.20^{\mathrm{bAB}}$ & $61.54 \pm 0.11^{\mathrm{aB}}$ & $60.72 \pm 0.34^{\mathrm{bAB}}$ \\
\hline 4 & $60.81 \pm 0.34^{\mathrm{aB}}$ & $57.78 \pm 0.59^{\mathrm{bBC}}$ & $61.03 \pm 0.24^{\mathrm{aB}}$ & $59.12 \pm 0.61^{\mathrm{bBC}}$ \\
\hline 6 & $59.90 \pm 0.14^{\mathrm{aB}}$ & $56.44 \pm 0.80^{\mathrm{bCD}}$ & $59.52 \pm 0.19^{\mathrm{C}}$ & $58.63 \pm 0.42^{\mathrm{C}}$ \\
\hline 8 & $58.42 \pm 0.33^{\mathrm{aC}}$ & $55.49 \pm 0.42^{\mathrm{bD}}$ & $58.03 \pm 0.58^{\mathrm{aD}}$ & $54.72 \pm 0.60^{\mathrm{bD}}$ \\
\hline
\end{tabular}

EM, Electro-magnetic resonance freezing; AB, Air blast freezing.

${ }^{\mathrm{a}, \mathrm{b}}$ Means within row with different superscripts are significantly different by freezing $(p<0.05)$.

${ }^{\text {A-D }}$ Means within column with different superscripts are significantly different by time $(p<0.05)$.

the beef stored by the electro-magnetic resonance freezing was better because the cell membrane of muscle tissue is less damaged and the drip from the beef, when it is thawed, is less. Depending on the frozen storage, the loin showed that the thawing loss increased from the range of $0.66-0.92 \%$ in the initial freezing period to $2.43-3.10 \%$ after 8 mon, regardless of the freezing methods $(p<0.05)$. The thawing loss of the round by the electro-magnetic resonance freezing also showed this similar trend to the loin $(p<0.05)$. In this study showed we had similar results with the report in which the storage of chicken and pork elapsed and the thawing losses were increased (Choe, 1980; Chung et al., 1981; Gong and Moon, 1987; Miller et al., 1980). The round was higher than the loin of 0.66$3.10 \%$ at $1.25-4.39 \%$. These results are to confirm the connection between ice crystal size and the ultrastructure, and we considered that because the ice crystal size of the round is small. The ice crystals were distributed a lot, and, since the moisture content is higher than the loin, the thawing loss is higher. The increase of thawing loss during the frozen storage has been reported as a result that occurs when the ice crystal gradually becomes larger while the ice crystals with relatively large steam pressure are gathered the in surrounding small ice crystals (Petzold et al., 2009). Skelly et al. (1973) have reported that the drip loss decreased as the fatness is increased, but in this study, we considered a similar result with the thawing loss of the loin being lower than the round. The cell wall collapsed from the formation of ice during frozen storage. It has been reported that the consequent irregular pattern is formed because the same components, such as the intracellular nutrient components, are separated from the tissue cells (Bomben et al., 1983). Thus, we considered the electro-magnetic resonance freezing to have a better thawing loss and that the quality change that occurred during the frozen storage may be reduced because the damage of the tissue cells is low.

\section{Water holding capacity (WHC)}

The change in the water holding capacity on electromagnetic resonance and the air blast freezing in loin and round during storage is shown in Table 3. The water holding capacity of meat is explained in the capacity of retaining moisture when the external physical treatment is applied. The water holding capacity has an effect on the quality of frozen meat, and affects the juiciness and tenderness (Forrest et al., 1975). Grau et al. (1953) has reported that about $65 \%$ of the water holding capacity originated from the fibrous protein, such as myosin or actin. The initial water holding capacity of the loin by the electro-magnetic resonance freezing was $62.24 \%$, but this result was reduced up to $58.42 \%$ on the 8 mon by the reduc- 
tion of the storage elapsed $(p<0.05)$. The water holding capacity according to the electro-magnetic resonance freezing and the air blast freezing during the storage of loin was $58.42-62.24 \%$ and $55.49-59.59 \%$, respectively. The water holding capacity of the loin by the electro-magnetic resonance freezing was significantly higher than those by the air blast freezing $(p<0.05)$. The water holding capacity of the round was reduced as the storage become longer, but the round by the electro-magnetic resonance freezing was $63.32 \%$ in the early stage. The water holding capacity of round in the electro-magnetic field and the air blast freezing treatment plot were reduced $5.29 \%$ and $5.60 \%$, respectively. Farouk and Swan (1998) have reported that the storage elapsed and the small ice crystals bonded each other. Because the recrystallization that forms the large ice crystals occurred, the water holding capacity is influenced by the recrystallization. These results agree with Bae (1987) who showed that the water holding capacity of pork was gradually reduced during the frozen storage of the pork up to 10 mon. Pearson and Miller (1950) have reported that the reduction of the water holding capacity according to the elapse of storage time is related to the increase of drip. Therefore, it has been reported that the water holding capacity of meat was reduced in accordance with the freezing and the elapse of storage period (Law et al., 1967; Miller et al., 1962; Oh et al., 1984; Park, 1991), and, also, it showed the difference was dependent on the freezing methods. Berry (1990) has reported that the cooling temperature and speed have an effect on the water holding ability. In this study, the result showed that the water holding capacity in the electro-magnetic resonance freezing was higher than that of the air blast freezing.

\section{Sensory characteristic}

The change in the sensory characteristics according to the frozen storage of the loin and round by the electromagnetic resonance and the air blast freezing is shown in Table 4. The flavor and taste of the loin by the electromagnetic resonance freezing was significantly higher

Table 4. Changes in sensory characteristics on electro-magnetic resonance and air blast freezing of loin and round during frozen storage for 8 mon (Unit: score)

\begin{tabular}{|c|c|c|c|c|c|}
\hline & & \multicolumn{2}{|c|}{ Loin } & \multicolumn{2}{|c|}{ Round } \\
\hline & & EM & $\mathrm{AB}$ & EM & $\mathrm{AB}$ \\
\hline \multirow{5}{*}{ Appearance } & 0 & $7.56 \pm 0.73^{\mathrm{A}}$ & $7.11 \pm 1.05^{\mathrm{A}}$ & $7.56 \pm 0.53^{\mathrm{aA}}$ & $6.11 \pm 0.78^{b}$ \\
\hline & 2 & $7.71 \pm 0.32^{\mathrm{A}}$ & $7.14 \pm 0.69^{\mathrm{A}}$ & $6.85 \pm 0.55^{\mathrm{B}}$ & $6.43 \pm 0.79$ \\
\hline & 4 & $7.29 \pm 0.76^{\mathrm{aAB}}$ & $6.00 \pm 1.00^{\mathrm{bB}}$ & $6.57 \pm 0.53^{\mathrm{B}}$ & $6.14 \pm 0.90$ \\
\hline & 6 & $6.71 \pm 0.49^{\mathrm{B}}$ & $6.00 \pm 0.82^{\mathrm{B}}$ & $6.43 \pm 0.53^{\mathrm{B}}$ & $6.29 \pm 0.49$ \\
\hline & 8 & $6.71 \pm 0.76^{\mathrm{B}}$ & $5.86 \pm 0.90^{\mathrm{B}}$ & $6.29 \pm 0.76^{\mathrm{B}}$ & $6.14 \pm 0.69$ \\
\hline \multirow{5}{*}{ Flavor } & 0 & $7.78 \pm 0.67^{\mathrm{aA}}$ & $6.56 \pm 0.88^{\mathrm{bAB}}$ & $7.44 \pm 0.73^{\mathrm{aA}}$ & $6.00 \pm 0.87^{b}$ \\
\hline & 2 & $7.81 \pm 0.72^{\mathrm{aA}}$ & $7.00 \pm 0.58^{\mathrm{bA}}$ & $7.68 \pm 0.73^{\mathrm{aA}}$ & $6.71 \pm 0.95^{\mathrm{b}}$ \\
\hline & 4 & $7.43 \pm 0.98^{\mathrm{aAB}}$ & $6.29 \pm 0.95^{\mathrm{bAB}}$ & $7.00 \pm 0.58^{\mathrm{AB}}$ & $4.61 \pm 0.98$ \\
\hline & 6 & $6.71 \pm 0.76^{\mathrm{BC}}$ & $6.00 \pm 0.82^{\mathrm{B}}$ & $6.57 \pm 0.53^{\mathrm{B}}$ & $6.43 \pm 0.53$ \\
\hline & 8 & $6.29 \pm 1.11^{\mathrm{C}}$ & $6.00 \pm 0.58^{\mathrm{B}}$ & $6.57 \pm 0.98^{\mathrm{B}}$ & $6.14 \pm 0.69$ \\
\hline \multirow{5}{*}{ Texture } & 0 & $8.00 \pm 0.50^{A}$ & $6.78 \pm 1.48^{\mathrm{AB}}$ & $7.89 \pm 0.78^{\mathrm{a} A}$ & $6.67 \pm 1.32^{\mathrm{bA}}$ \\
\hline & 2 & $7.81 \pm 0.75^{\mathrm{A}}$ & $7.00 \pm 0.58^{\mathrm{A}}$ & $7.63 \pm 0.74^{\mathrm{aA}}$ & $6.71 \pm 0.95^{\mathrm{bA}}$ \\
\hline & 4 & $7.43 \pm 0.98^{\mathrm{aAB}}$ & $6.43 \pm 0.98^{\mathrm{bAB}}$ & $6.71 \pm 0.76^{\mathrm{B}}$ & $6.36 \pm 1.07^{\mathrm{AB}}$ \\
\hline & 6 & $6.71 \pm 0.76^{\mathrm{B}}$ & $5.86 \pm 0.69^{\mathrm{B}}$ & $6.57 \pm 0.53^{\mathrm{aB}}$ & $6.00 \pm 0.58^{\mathrm{bAB}}$ \\
\hline & 8 & $6.57 \pm 0.98^{\mathrm{B}}$ & $5.57 \pm 0.98^{\mathrm{B}}$ & $6.43 \pm 0.53^{\mathrm{B}}$ & $5.57 \pm 0.79^{\mathrm{B}}$ \\
\hline \multirow{5}{*}{ Taste } & 0 & $7.56 \pm 0.53^{\mathrm{aAB}}$ & $6.22 \pm 1.20^{\mathrm{bB}}$ & $7.89 \pm 1.17^{\mathrm{aA}}$ & $6.78 \pm 0.97^{b}$ \\
\hline & 2 & $7.83 \pm 0.74^{\mathrm{aA}}$ & $7.00 \pm 0.58^{\mathrm{bA}}$ & $7.65 \pm 0.77^{\mathrm{aA}}$ & $6.71 \pm 0.95^{\mathrm{b}}$ \\
\hline & 4 & $7.43 \pm 0.79^{\mathrm{aAB}}$ & $6.29 \pm 0.95^{\mathrm{bB}}$ & $7.00 \pm 0.82^{\mathrm{AB}}$ & $6.43 \pm 0.98$ \\
\hline & 6 & $6.71 \pm 0.76^{\mathrm{B}}$ & $6.14 \pm 0.90^{\mathrm{B}}$ & $6.57 \pm 0.53^{\mathrm{B}}$ & $6.14 \pm 0.69$ \\
\hline & 8 & $6.71 \pm 0.49^{\mathrm{B}}$ & $6.00 \pm 0.82^{\mathrm{B}}$ & $6.29 \pm 0.76^{\mathrm{B}}$ & $5.86 \pm 1.07$ \\
\hline \multirow{5}{*}{ Overall acceptability } & 0 & $8.00 \pm 0.50^{\mathrm{aA}}$ & $6.89 \pm 1.36^{\mathrm{bA}}$ & $7.89 \pm 1.17^{\mathrm{aA}}$ & $6.78 \pm 1.20^{b}$ \\
\hline & 2 & $7.86 \pm 0.74^{\mathrm{aA}}$ & $7.00 \pm 0.58^{\mathrm{bA}}$ & $7.65 \pm 0.78^{\mathrm{aA}}$ & $6.71 \pm 0.95^{\mathrm{b}}$ \\
\hline & 4 & $6.57 \pm 0.53^{\mathrm{B}}$ & $6.29 \pm 0.95^{\mathrm{AB}}$ & $6.43 \pm 0.98^{\mathrm{B}}$ & $6.30 \pm 0.95$ \\
\hline & 6 & $6.77 \pm 0.76^{\mathrm{B}}$ & $5.86 \pm 0.90^{\mathrm{B}}$ & $6.57 \pm 0.53^{\mathrm{B}}$ & $6.29 \pm 0.95$ \\
\hline & 8 & $6.43 \pm 0.98^{\mathrm{B}}$ & $5.71 \pm 0.76^{\mathrm{B}}$ & $6.29 \pm 0.76^{\mathrm{B}}$ & $5.86 \pm 0.69$ \\
\hline
\end{tabular}

EM, Electro-magnetic resonance freezing; AB, Air blast freezing.

${ }^{a, b}$ Means within row with different superscripts are significantly different by freezing $(p<0.05)$.

${ }^{\text {A-D }}$ Means within column with different superscripts are significantly different by time $(p<0.05)$. 
than that of the air blast freezing $(p<0.05)$. The overall acceptability of the loin by the electro-magnetic resonance freezing showed a higher score than that of the loin by the air blast freezing. The appearance, flavor, texture, and overall acceptability showed that the difference according to the freezing storage, and they were received sensorially with a gradually poor evaluation according to the elapse of the freezing storage $(p<0.05)$. The round showed the tendency to receive lower scores in all items, according to the elapse of the storage $(p<0.05)$. The beef stored by using the electro-magnetic resonance freezing showed high overall acceptability, and it is considered that the sensory characteristics degradation during the frozen storage can be reduced when the electro-magnetic field freezing was applied rather than the air blast freezing.

\section{Conclusion}

The change in ultrastructure and quality characteristics during the frozen storage of the loin and round by the electro-magnetic resonance and the air blast freezing were investigated. The initial ice crystal size of the loin and round by the electro-magnetic resonance freezing was smaller and had a more uniform state, and they also showed a lower thawing loss in comparison with the air blast freezing. The ice crystal size of loin was smaller than the round and also had a lower the thawing loss. As the frozen storage time became longer, the ice crystal size and the thawing loss increased. It is considered that the results that the electro-magnetic resonance freezing shows lower increase and decrease ratio of the thawing loss and the water holding capacity according to the frozen storage in comparison with the air blast freezing is because the shape and ice crystal size were small and uniformly formed in the early stage. The electro-magnetic resonance freezing showed the higher overall acceptability during the frozen storage in comparison with the air blast freezing. In conclusion, it is considered that the electro-magnetic resonance freezing may reduce the ultrastructure and sensory characteristics degradation at the time of the long-term storage.

\section{Acknowledgements}

This research was supported High Value added Food Technology Development Program (2014-314068-3) by the Ministry of Agriculture, Food and Rural Affairs (Republic of Korea).

\section{References}

1. Alizadeh, E., Chapleau, N., De Lamballerie, M., and Le-Bail, A. (2007) Effect of differentfreezing process on the ultrastructure of atlantic salmon (Salmon salar) fillets. Innov. Food Sci. Emerg. 8, 493-499.

2. Bae, K. H. (1987) A study on the storage method of frozen pork. Ph. M. thesis. Konkuk Univ., Seoul, Korea.

3. Bello, R. A., Luft, J. H., and Pigott, G. M. (1982) Ultrastructural study of skeletal fish muscle after freezing at different rates. J. Food Sci. 47, 1389-1394.

4. Bergara-Almeida, S. and da Silva, M. A. A. P. (2002) Hedonic scale with reference: Performance in obtaining predictive models. Food Qual. Prefer. 13, 57-64.

5. Berry, B. W. (1990) Changes in quality of all-beef and soyextended patties as influenced by freezing rate, frozen storage temperature, and storage time. J. Food Sci. 55, 893-897.

6. Bomben, J. L., King, C. J., and Hayes, T. L. (1983) Cold-stage scanning electron microscope measurement of ice morphology in apple tissue as a function of freezing rate. Cryobiology 20, 574-586.

7. Brennan, J. G., Butters, J. R., Cowell, N. D., and Lilly, A. E. V. (1990) Food Engineering Operations (3rd ed.). Elsevier, Amsterdam, pp. 15- 532.

8. Chassagne-Berces, S., Poirier, C., Devaux, M., and Fonseca, F. (2009) Changes in texture, cellular structure and cell wall composition in apple tissue as a result of freezing. Food Res. Int. 42, 788-797.

9. Choe, B. K. (1980) Studies on the quality changes of chicken muscle during cold storage. Korean J. Anim. Sci. Technol. 22, 516-527.

10. Chung, K. Y., Choe, B. K., and Hwang, C. S. (1981) The experimental study I. lipid changes of defrozen chicken muscle during cold storage. Korean J. Anim. Sci. Technol. 23, 553572.

11. Farouk, M. M. and Swan, J. E. (1998) Effect of rigor temperature and frozen storage on functional properties of hotboned manufacturing beef. Meat Sci. 49, 223-247.

12. Fennema, O. R., Powrie, W. D., and Marth, E. H. (1973) Nature of the freezing process. In: Low temperature preservation of foods and living matter. Marcel Dekker, New York, pp. 151-222.

13. Forrest, T. C., Aberle, E. B., Hedrick, H. B., Judge, M. D., and Merkel, R. A. (1975) Principles of meat science. W. H. Freeman and Company, USA. pp. 174-417.

14. Gong, Y. S. and Moon, Y. H. (1987) Changes in the physicochemical properties of spent-hen meat during cold and frozen storage. J. Korean Soc. Food Nutr. 16, 55-61.

15. Grau, R., Hamm, R., and Braumann, A. (1953) Uber das wasserbindungsvermogen des toten saugetier muskel biochem. Nahrung 2, 325-326.

16. Iwasaka, M., Onishi, M., Kurita, S., and Owada, N. (2011) Effects of pulsed magnetic fields on the light scattering property of the freezing process of aqueous solutions. J. Appl. Phys. 109, 320-323.

17. Jeong, J. W., Lee, H. J., and Park, N. H. (1999) Changes in 
quality during frozen storage of meat with thermal equalized freezing. Korean J. Food Sci. Technol. 31, 688-696.

18. Kalichevsky, M. T., Knorr, D., and Lillford, P. J. (1995) Potential food applications of high-pressure effects on ice-water transitions. Trends in Food Sci. Technol. 6, 253-259.

19. Kidmose, U. and Martens, H. J. (1999) Canges in texture, ultrastructure and nutritional quality of carrot slices during blanching and freezing. J. Sci. Food Agri. 79, 1747-1753.

20. Kim, N. K. and Hung, Y. C. (1994) Freeze-cracking in foods as affected by physical properties. J. Food Sci. 59, 669-674.

21. Kristensen, L. and Purslow, P. P. (2001) The effect of ageing on the water-holding capacity of pork: Role of cytoskeletal proteins. Meat Sci. 58, 17-23.

22. Lakshmisha, I. P., Ravishankar, C. N., Ninan, G., Mohan, Co O., and Gopal, T. K. S. (2008) Effect of freezing time on the quality of Indian mackerel curing frozen storage. J. Food Sci. 73, S345-S353.

23. Lawless, H. T. and Heymann, H. (1999) Sensory evaluation of food: principles and practices. New York: Chapman \& Hall, An Aspen Publication.

24. Law, H. M., Yang, S. P., Mullis, A. M., and Fielder, M. M. (1967) Effect of storage and cooking on qualities of loin and top-round steaks. J. Food Sci. 32, 637-641.

25. Martino, M. N., Otero, L., Sanz, P. D., and Zaritzky, N. E. (1998) Size and location of ice crystals in pork frozen by highpressure-assisted freezing as compared to classical methods. Meat Sci. 50, 303-313.

26. Miller, A. J., Ackerman, S. A., and Palumbo, S. A. (1980) Effects of frozen storage on functionality of meat for processing. J. Food Sci. 45, 1466-1471.

27. Miller, W. O., Saffle, R. L., and Zirkle, S. B. (1962) Factors which influence the water-holding capacity of various types of meat. J. Food Technol. 16, 72-77.

28. Norton, T., Delgado, A. E., Hogan, E., Grace, T., and Sin, D. W. (2009) Simulation of high pressure freezing process by enthalpy methods. J. Food Eng. 91, 260-268.

29. Oh, K. S., Cho, S. Y., Cha, Y. J., and Lee, E. H. (1984) Processing conditions and quality stability of sardine steak during frozen storage. Korean J. Food Sci. Technol. 16, 133138.

30. Otero, L., Martino, M., Zaritzky, N., Solas, M., and Sanz, P. D. (2000) Preservation of ultrastructure in peach and mango during high-pressure-shift freezing. J. Food Sci. 65, 466-470.

31. Park, H. S. (1991) Changes in quality of fabricated crab leg meat during cold and frozen storage. Ph. M. thesis, Kyungsung Univ., Busan, Korea.

32. Pearson, A. M. and Miller, J. I. (1950) The influence of rate of freezing and length of freezing storage upon the quality of beef of known origin. J. Anim. Sci. 9, 13-16.

33. Petzold, G. and Aguilera, J. M. (2009) Ice morphology: Fundamentals and technological applications in foods. Food Biophysics 4, 378-396.

34. Reid, D. S. (1997) Overview on physical/chemical aspects of freezing. In: Quality in frozen food. M.C. Erickson, and C.Y. Hung (eds.). Chapman and Hall, New York, pp.10-28.

35. SAS (2002) SAS/STAT Software for PC. Release 9.0, SAS Institute Inc., Cary, NC, USA.

36. Skelly, G. C., Hardlin, D. L., and Bonnette, T. E. (1973) Pork acceptability and its relationship to carcass quality. J. Anim. Sci. 36, 488-492.

(Received 2014.8.4/Revied 2018.9.2/Accepted 2014.9.2) 